\title{
Effects of calcium carbonate on the fermentation quality and aerobic stability of total mixed ration silage
}

\author{
P. Tian', D. Vyas' ${ }^{2}$, D. Niu', S. Zuo', Di Jiang' and Ch. Xu' ${ }^{1,3}$ \\ ${ }^{1}$ China Agricultural University, College of Engineering, 17 Qinghua East Road, Haidian District, Beijing,China \\ ${ }^{2}$ University of Florida, Department of Animal Sciences, 2250 Shealy Drive, 32611, Gainesville, FL, USA
}

KEY WORDS: aerobic stability, calcium carbonate, high moisture, microbial count, total mixed ration silage

Received: 4 December 2019

Revised: $\quad 19$ May 2020

Accepted: $\quad 9$ June 2020

${ }^{3}$ Corresponding author:

e-mail: xucc@cau.edu.cn

\begin{abstract}
The aim of the study was to evaluate the effects of calcium carbonate (CCA) on the fermentation quality, aerobic stability and microbial counts during the aerobic deterioration of two high moisture total mixed ration (TMR) silages. The alfalfa hay, sweet potato residue, maize flour, soybean meal, molasses and vitamin-mineral supplement were mixed on a dry matter (DM) basis in the rations of 40:30:18:9:2:1, respectively, to prepare TMR. The moisture level of TMR silage was adjusted to 600 (medium) and $750 \mathrm{~g} / \mathrm{kg}$ (high) before ensiling with 0,5,15 and $25 \mathrm{~g} / \mathrm{kg} \mathrm{CCA} \mathrm{(on} \mathrm{a} \mathrm{fresh} \mathrm{weight}$ (FW) basis). The fermentation quality, chemical composition, microbial counts and aerobic stability of TMR were assessed after 150 days of ensiling. It was observed that $\mathrm{pH}$, lactic acid, acetic acid, ammonia nitrogen and the population of lactic acid bacteria $(\mathrm{LAB})$ were influenced $(P<0.05)$ by moisture level, CCA application and their interaction. Likewise, adding increasing amounts of CCA increased aerobic stability $(P<0.05)$ of the TMR silage from 18.4 to 23.7 days and from 3.7 to 11.5 days at medium and high moisture level, respectively. Moreover, it was observed that the growth of yeasts and aerobic bacteria were inhibited by the CCA application during the aerobic deterioration. The application of CCA additive is an appropriate strategy for improving fermentation quality and aerobic stability of both relatively high moisture TMR silages.
\end{abstract}

\section{Introduction}

Total mixed ration (TMR) silage has been commonly used in Asian countries because of its balanced nutrients, good aerobic stability and easy transportation (Xu et al., 2007; Weinberg et al., 2011; Miyaji et al., 2017). In the previous study we have indicated that TMR silage increases the digestibility of crude protein $(\mathrm{CP})$, ether extract and acid detergent fibre (ADF) and decreases ruminal methane emissions and energy loss of sheep in comparison to unfermented TMR (Cao et al., 2010). Moreover, TMR silage reduces urinary $\mathrm{N}$ loss without adverse effects on feed intake, milk production and ruminal fermentation of lactating cows (Miyaji et al., 2013).
However, high moisture content and prolonged ensiling caused excessive acidification of TMR silage especially during the summer season (Hao et al., 2015). The over-acidification leads to a decline in silage palatability which often reduces feed intake and growth performance of livestock (Gao and Oba, 2014; Oladosu et al., 2016). Furthermore, high moisture content of TMR promotes undesirable microbes including aerobic bacteria and moulds which may lead to lower aerobic deterioration after unsealing (Hao et al., 2015; Wang et al., 2016). The additives for TMR silages under high moisture and prolonged ensiling condition may improve TMR fermentation and safer salts have been proposed as alternative silage additives (Oladosu et al., 2016). 
In previous studies it was observed that the addition of 1 or $1.5 \%$ calcium carbonate (CCA) prior to ensiling increased the organic acid content and aerobic stability of silage (Klosterman et al., 1960; Li et al., 1992; Niu et al., 2018). However, the information on optimum amounts of CCA to be added and the effect of CCA on improving aerobic stability of high moisture TMR silage is lacking. We hypothesized that CCA may improve the fermentation quality by increasing the organic acid content and improving the aerobic stability of TMR silage by its buffering ability characteristics.

So, the objective of this study was to investigate the effect of various concentrations of CCA on fermentation quality, chemical composition, aerobic stability and microbial characteristics of TMR silage at two relatively high moisture levels.

\section{Material and methods}

\section{Total mixed ration (TMR) silage preparation}

The ingredients and chemical composition of medium and high moisture levels of TMR are presented in Table 1. TMR was formulated

Table 1. Ingredient proportions, chemical composition and microbial counts of total mixed rations at different moisture levels

\begin{tabular}{lcc}
\hline \multirow{2}{*}{ Indices } & \multicolumn{2}{c}{ Total mixed rations (TMR) } \\
\cline { 2 - 3 } & M-TMR & H-TMR \\
\hline Ingredient, g/kg DM & & \\
$\quad$ alfalfa hay & 400 & 400 \\
sweet potato residue & 300 & 300 \\
maize meal & 180 & 180 \\
soybean meal & 90 & 90 \\
vitamin-mineral supplement ${ }^{1}$ & 10 & 10 \\
molasses & 20 & 20 \\
Chemical composition, g/kg DM & \\
DM, g/kg FW & 375 & 234 \\
CP & 168 & 162 \\
WSC & 135 & 138 \\
NDF & 288 & 285 \\
ADF & 222 & 216 \\
Microbial counts, log & cfu/g FW & \\
LAB & 8.86 & 8.78 \\
aerobic bacteria & 4.79 & 4.65 \\
yeasts & 4.29 & 4.32 \\
moulds & 3.35 & 3.31 \\
\hline
\end{tabular}

M-TMR - TMR with medium moisture content, H-TMR - TMR with high moisture content, DM - dry matter, FW - fresh weight, CP - crude protein, WSC - water-soluble carbohydrates, NDF - neutral detergent fibre, ADF - acid detergent fibre, $L A B$ - lactic acid bacteria, $A B$ - aerobic bacteria, cfu - colony forming units; ${ }^{1}$ contained per kg, g: Zn 12 , $\mathrm{Mn} \mathrm{10,} \mathrm{Fe} \mathrm{5,} \mathrm{Cu} \mathrm{2;} \mathrm{IU:} \mathrm{vit.} \mathrm{A/g} \mathrm{min.} \mathrm{5000,} \mathrm{vit.} \mathrm{D/g} 600$ with alfalfa hay, sweet potato residue, maize flour, soybean meal, molasses and vitamin-mineral supplement on a dry matter (DM) basis in the ratio of 40:30:18:9:2:1, respectively. Then, moisture levels of TMR were adjusted to 600 (medium, M-TMR) and $750 \mathrm{~g} / \mathrm{kg}$ (high, H-TMR) by adding different content of sterile water. TMR for each moisture level was ensiled with $0,5,15$ and $25 \mathrm{~g} / \mathrm{kg}$ of fresh weight (FW) CCA (purity $\geq 99 \%$; Shanghai Mclean Biochemical Science and Technology Co., Ltd., Shanghai, China). Treatments were defined as M0, M5, M15 and M25 for medium, and $\mathrm{H} 0, \mathrm{H} 5, \mathrm{H} 15$ and $\mathrm{H} 25$ for high moisture TMR ensiled with $0,5,15$ and $25 \mathrm{~g} / \mathrm{kg}$ of CCA, respectively. After uniform mixing about $2 \mathrm{~kg}$ TMR were put into a laboratory polyethylene plastic bags. All bags were degassed, sealed with a vacuum packing machine (BH950, Matsushita, Osaka, Japan) and then stored at an ambient temperature $\left(27\right.$ to $\left.35^{\circ} \mathrm{C}\right)$. After 150 days of ensiling, triplicate bags for each treatment were unsealed and sampled for fermentation quality analyses. The remaining TMR silage samples were used for aerobic stability determination.

\section{Chemical analyses}

At sampling, each TMR silage was put into an ethanol-disinfected plastic container and mixed uniformly. For the determination of DM, the collected samples were immediately put in a forced draft oven for $48 \mathrm{~h}$ at $65^{\circ} \mathrm{C}$ (AOAC, 2000). Dried samples were then ground to pass a $1-\mathrm{mm}$ screen with a laboratory knife mill (FW100, Taisite Instrument Co., Ltd., Tianjin, China) and then used for chemical analysis. The CP and contents of water-soluble carbohydrates (WSC) were determined following the methods described by AOAC (2000) and Thomas (1977), respectively. The method described by Van Soest et al. (1991) was adopted for the determination of neutral detergent fibre (NDF) and ADF.

Silage extract was prepared by mixing a $10-\mathrm{g}$ silage sample with $90 \mathrm{ml}$ autoclaved sterilized water and then it was homogenized for $30 \mathrm{~s}$ by a vortex shaker (QL-866, Kylin-Bell, Haimen, China). Silage extract was used for the determination of fermentation quality. The $\mathrm{pH}$ of the extract was measured using a glass electrode $\mathrm{pH}$ meter $(\mathrm{S} 20 \mathrm{~K}$, Mettler Toledo, Greifensee, Switzerland). The concentrations of lactic acid, acetic acid, propionic acid and butyric acid were determined using a high-performance liquid chromatography (Showa Denko K.K., Kawasaki, Japan, with Shodex RS Pak KC-811 column, detector: DAD $210 \mathrm{~nm}$, eluent: 
$3 \mathrm{mmol} / 1 \mathrm{HClO}_{4}, 1.0 \mathrm{ml} / \mathrm{min}$; column temperature: $50{ }^{\circ} \mathrm{C}$ ) while the concentration of ammonia nitrogen was determined according to the method described by Broderick and Kang (1980).

\section{Microbial population}

Silage extract prepared for determination of fermentation quality was serially diluted from $10^{-2}$ to $10^{-7}$ for the estimation of microbial counts. For the enumeration of lactic acid bacteria (LAB), de Man, Rogosa and Sharpe agar (Difco Laboratories, Detroit, MI, USA) media were employed. The agar plates were incubated in an anaerobic incubator (YQX-II CIMO Medical Instrument Manufacturing Co., Ltd, Shanghai, China) at $37{ }^{\circ} \mathrm{C}$ for 2 days. Mould and yeast were counted on a potato dextrose agar (Nissui, Tokyo, Japan) media incubated for 2 days at $30{ }^{\circ} \mathrm{C}$ under aerobic conditions. The count of aerobic bacteria was determined on a nutrient agar (Nissui-Seiyaku Ltd., Tokyo, Japan) media for 2 days at $30{ }^{\circ} \mathrm{C}$ under aerobic conditions. All microbial data were transformed to $\log _{10}$ and are presented on a FW basis.

\section{Aerobic stability}

The same bags after sampled for fermentation quality were used to determine aerobic stability. After thorough mixing, TMR silage from each bag was placed into new sterile polyethylene barrels of $51 \mathrm{ca}-$ pacity separately without compaction, kept uncovered and stored at ambient temperature $\left(29-33{ }^{\circ} \mathrm{C}\right)$. After every two days, 10 -g samples were taken for the determination of $\mathrm{pH}$ and microbial population until aerobic deterioration. During aerobic stability test, the temperature was automatically monitored at 1 -h intervals by a thermocouple wire connected to a data logger (DT85 series2, Data Taker, Melbourne, Australia). The test was replicated thrice for getting statistically reliable results. Aerobic stability is defined as the number of $h$ that the silage remained stable before increasing temperature around $2{ }^{\circ} \mathrm{C}$ above the ambient temperature. We converted $h$ into days to express the aerobic stability in the present study.

\section{Statistical analyses}

Data on fermentation quality and chemical composition of TMR silage were subjected to a two-way analysis of variance (ANOVA) with a fixed effect of CCA dosages and moisture levels while a one-way ANOVA was used for the analysis of the significant difference between the aerobic stability of TMR silage. Data were compared by Tukey's multiple test and significance differences were noted at $P<0.05$. All statistical analyses were conducted using a SPSS 20.0 (IBM Corp., Armonk, NY, USA).

\section{Results}

\section{Fermentation quality of TMR silage}

The effects of CCA and moisture levels on fermentation quality of TMR are presented in Table 2. Dose-dependent effects were observed on $\mathrm{pH}$ values - increasing doses of CCA increased $\mathrm{pH}$ levels of TMR silage $(P<0.001)$. The interaction between CCA and moisture levels was significant for the $\mathrm{pH}$ levels $(P<0.001)$. Greater moisture content of TMR silage (H-TMR) improved $\mathrm{pH}$ levels with 0 and $5 \mathrm{~g} / \mathrm{kg} \mathrm{CCA}$; however, $\mathrm{pH}$ levels were greater with 15 and $25 \mathrm{~g} / \mathrm{kg}$ CCA addition to the M-TMR

Table 2. Fermentation quality of total mixed ratios (TMR) ensiled with different levels of calcium carbonate (CCA) after 150 days of ensiling

\begin{tabular}{|c|c|c|c|c|c|c|c|c|c|c|c|c|}
\hline \multirow[t]{2}{*}{ Indices } & \multicolumn{4}{|c|}{$\begin{array}{l}\text { M-TMR silage }{ }^{1} \\
\text { Level of CCA }\end{array}$} & \multicolumn{4}{|c|}{$\begin{array}{l}\text { H-TMR silage } \\
\text { Level of CCA }\end{array}$} & \multirow[t]{2}{*}{ SEM } & \multicolumn{3}{|l|}{$P$-value } \\
\hline & 0 & 5 & 15 & 25 & 0 & 5 & 15 & 25 & & $\overline{\mathrm{CCA}}$ & $\mathrm{ML}$ & $\mathrm{ML} \times \mathrm{CCA}$ \\
\hline $\mathrm{pH}$ & $3.79^{H}$ & $4.02^{\mathrm{G}}$ & $4.44^{\mathrm{B}}$ & $4.67^{\mathrm{A}}$ & $4.10^{\mathrm{F}}$ & $4.22^{\mathrm{E}}$ & $4.25^{\mathrm{D}}$ & $4.30^{c}$ & 0.052 & $<0.001$ & 0.044 & $<0.001$ \\
\hline Lactic acid, g/kg DM & $42.4^{\mathrm{B}}$ & $65.5^{\mathrm{A}}$ & $70.4^{\mathrm{A}}$ & $72.4^{\mathrm{A}}$ & $25.0^{C}$ & $42.8^{B}$ & $73.9^{A}$ & $74.7^{\mathrm{A}}$ & 3.833 & $<0.001$ & 0.003 & 0.002 \\
\hline Acetic acid, g/kg DM & $7.0^{\mathrm{E}}$ & $22.3^{\mathrm{D}}$ & $32.5^{\mathrm{BCD}}$ & $38.4^{\mathrm{BC}}$ & $23.9^{C D}$ & $37.3^{\mathrm{BC}}$ & $40.9^{\mathrm{B}}$ & $54.8^{\mathrm{A}}$ & 3.11 & $<0.001$ & $<0.001$ & 0.777 \\
\hline Propionic acid, g/kg DM & $0.4 \mathrm{~F}$ & $0.8^{\mathrm{EF}}$ & $1.9^{\mathrm{DE}}$ & $2.6^{\mathrm{CD}}$ & $5.5^{\mathrm{A}}$ & $4.4^{\mathrm{AB}}$ & $3.5^{\mathrm{BC}}$ & $3.3^{\mathrm{BC}}$ & 0.35 & 0.775 & $<0.001$ & $<0.001$ \\
\hline Butyric acid, g/kg DM & ND & ND & ND & ND & ND & ND & ND & ND & - & - & - & - \\
\hline Ammonia nitrogen, $\%$ TN & $2.48^{\mathrm{E}}$ & $3.06^{\mathrm{DE}}$ & $5.09^{B C}$ & $5.98^{B}$ & $6.06^{\mathrm{B}}$ & $4.08^{\mathrm{CD}}$ & $5.65^{\mathrm{B}}$ & $7.52^{\mathrm{A}}$ & 0.348 & $<0.001$ & $<0.001$ & 0.008 \\
\hline Lactic acid bacteria, $\log _{10} \mathrm{cfu} / \mathrm{g} \mathrm{FW}$ & $7.8^{\mathrm{D}}$ & $8.34^{\mathrm{B}}$ & $8.31^{B}$ & $8.70^{\mathrm{A}}$ & $8.08^{C}$ & $8.40^{\mathrm{B}}$ & $7.58^{\mathrm{E}}$ & $7.68^{\mathrm{DE}}$ & 0.079 & $<0.001$ & $<0.001$ & $<0.001$ \\
\hline Yeasts, $\log _{10}$ cfu/g FW & ND & ND & ND & ND & ND & ND & ND & ND & - & - & - & - \\
\hline Aerobic bacteria, $\log _{10} \mathrm{cfu} / \mathrm{g} \mathrm{FW}$ & 3.26 & 3.19 & 3.25 & 3.12 & 3.28 & 2.86 & 2.96 & 2.80 & 0.061 & 0.296 & 0.062 & 0.673 \\
\hline
\end{tabular}

1,2 - see Table 1, DM - dry matter, TN - total nitrogen, FW - fresh weight, cfu - colony forming units, CCA - calcium carbonate, $\mathrm{ML}$ - moisture level, ML× CCA - interaction between moisture level and calcium carbonate, ND - not detected, SEM - standard error of the mean; ${ }^{A-H}$ - means in the same row with different superscripts are significantly different at $P<0.05$ 
silage. The lactic acid concentration was increased with CCA $(P<0.001)$ and with high moisture level of TMR $(P=0.003)$. The interaction effect between CCA and moisture level was significant $(P=0.002)$ as lactic acid concentration was greater with 0 and $5 \mathrm{~g} / \mathrm{kg}$ CCA for M-TMR in comparison to H-TMR. Lactic acid concentrations with 15 and $25 \mathrm{~g} / \mathrm{kg}$ CCA was similar regardless of moisture content of TMR silage. No interaction effect was observed for the acetic acid concentration; however, dose-dependent increase was observed with CCA addition to the TMR silage $(P<0.001)$. Similarly, greater acetic acid concentration was observed for H-TMR in comparison to M-TMR silage $(P<0.001)$. The efficacy of CCA at improving propionic acid concentration was greater with H-TMR in comparison to M-TMR silage at all dose levels of CCA $(P<0.001)$. Similar response was observed with ammonia nitrogen (as \% of total $\mathrm{N}$ ) as the efficacy of CCA was greater at 0 and $25 \mathrm{~g} / \mathrm{kg}$ levels with H-TMR silage in comparison to M-TMR silage $(P<0.001)$. Butyric acid and yeast were not detected in the TMR silage. The abundance of aerobic bacteria was not affected by CCA addition $(P=0.296)$; however, tendency for lower aerobic bacteria was observed with H-TMR silage $(P=0.062)$. LAB counts were greater with $0 \mathrm{~g} / \mathrm{kg}$ CCA while lower with 15 and $25 \mathrm{~g} / \mathrm{kg} \mathrm{CCA}$ for H-TMR silage $(P<0.001)$.

\section{Chemical composition of TMR silages}

The chemical composition of TMR silages after 150 days of ensiling is presented in Table 3. The DM levels were greater with $0,5,15$ and $25 \mathrm{~g} / \mathrm{kg}$ CCA for M-TMR silage $(P=0.01)$. No interaction was observed on the CP concentration; however, CCA addition elevated $\mathrm{CP}$ levels for the TMR silage $(P=0.022)$. WSC concentration were greater for H-TMR silage with 0 and $5 \mathrm{~g} / \mathrm{kg} \mathrm{CCA}(P<0.001)$. Similarly, an interaction was observed between CCA application and moisture level of the TMR silage for NDF and ADF concentrations $(P<0.001)$.

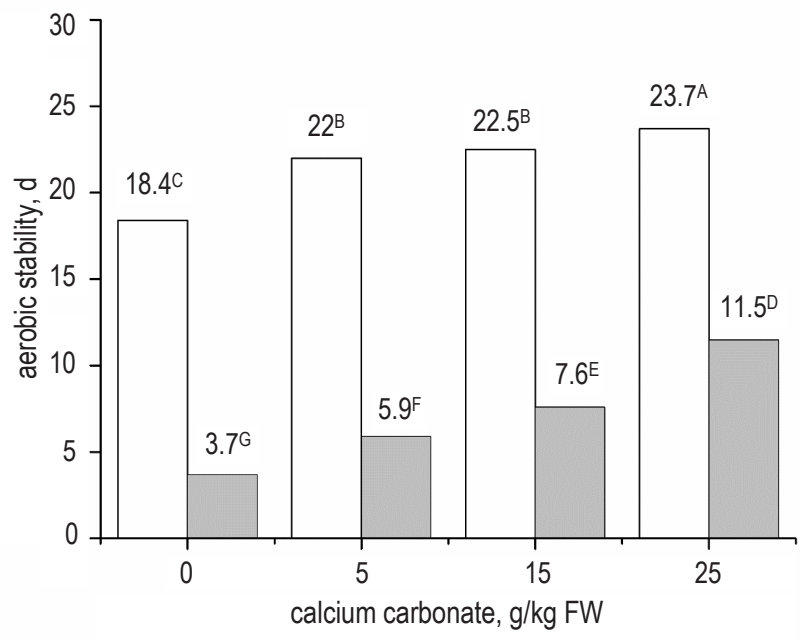

Figure 1. Aerobic stability of total mixed ration (TMR) silages treated with $0,5,15$ and $25 \mathrm{~g} / \mathrm{kg} \mathrm{FW}$ of calcium carbonate ensiled for 150 days. Bars with different superscripts differ at $P<0.05$; M-TMR - TMR with medium moisture content, H-TMR - TMR with high moisture content, FW - fresh weight; M-TMR silage ( $\square$ ); H-TMR silage ( $\square$ )

\section{Aerobic stability of TMR silages}

The aerobic stability of TMR silages prepared at both moisture levels increased $(P<0.05)$ (from 18.4 to 23.7 days and from 3.7 to 11.5 days for M-TMR and H-TMR, respectively) with an increase in CCA concentration (Figure 1). The aerobic stability of M-TMR silages was greater than of H-TMR silages. Moreover, during aerobic exposure, the $\mathrm{pH}$ values of M-TMR and H-TMR silages were ranged from 3.5-5.0 and 4.0-4.5, respectively (Figure 2). Slightly higher $\mathrm{pH}$ values were observed in $\mathrm{M} 0$ and $\mathrm{H} 0$ while other treatments remained at a stable level before deterioration. Besides, it was observed that the increase in CCA dosage caused an increase in $\mathrm{pH}$ for both M-TMR and H-TMR silages.

\section{Dynamics of microbial population during aerobic exposure}

The variations in the counts of viable microorganisms were observed in both M-TMR and H-TMR silages during aerobic exposure (Figure 3 and 4).

Table 3. Chemical composition of total mixed ratios (TMR) ensiled with different levels of calcium carbonate (CCA) after 150 days of ensiling

\begin{tabular}{|c|c|c|c|c|c|c|c|c|c|c|c|c|}
\hline \multirow{3}{*}{ Indices } & \multirow{2}{*}{\multicolumn{4}{|c|}{ 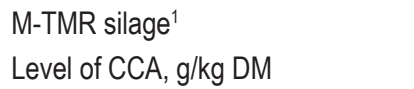 }} & \multicolumn{5}{|c|}{ H-TMR silage ${ }^{2}$} & \multirow{2}{*}{\multicolumn{3}{|c|}{$P$-value }} \\
\hline & & & & & \multicolumn{4}{|c|}{ Level of CCA, g/kg DM } & \multirow[t]{2}{*}{ SEM } & & & \\
\hline & $\overline{0}$ & 5 & 15 & 25 & 0 & 5 & 15 & 25 & & $\overline{\mathrm{CCA}}$ & $\mathrm{ML}$ & $\mathrm{ML} \times \mathrm{CCA}$ \\
\hline$\overline{D M}, \mathrm{~g} / \mathrm{kg} F W$ & $356^{A}$ & $353^{A B}$ & $355^{\mathrm{A}}$ & $351^{\mathrm{B}}$ & $216^{C}$ & $209^{D}$ & $217^{c}$ & $207^{D}$ & 14.7 & $<0.001$ & $<0.001$ & 0.010 \\
\hline $\mathrm{CP}, \mathrm{g} / \mathrm{kg} \mathrm{DM}$ & 167 & 166 & 173 & 172 & 166 & 167 & 172 & 172 & 0.9 & 0.022 & 0.788 & 0.995 \\
\hline WSC, g/kg DM & $99.8^{c}$ & $69.8^{\mathrm{D}}$ & $55.5^{\mathrm{E}}$ & $55.2^{\mathrm{E}}$ & $114.7^{\mathrm{A}}$ & $104.0^{B}$ & $48.8^{F}$ & $48.6^{\mathrm{F}}$ & 5.34 & $<0.001$ & $<0.001$ & $<0.001$ \\
\hline NDF, g/kg DM & $297^{A}$ & $276^{\mathrm{CD}}$ & $278^{\mathrm{CD}}$ & $279^{C D}$ & $295^{A B}$ & $283^{B C}$ & $277^{\mathrm{CD}}$ & $270^{D}$ & 2.2 & 0.017 & 0.682 & 0.001 \\
\hline ADF, g/kg DM & $230^{A}$ & $206^{c}$ & $206^{c}$ & $210^{B C}$ & $237^{\mathrm{A}}$ & $224^{A B}$ & $210^{B C}$ & $203^{c}$ & 2.8 & 0.016 & 0.104 & $<0.001$ \\
\hline
\end{tabular}

1,2 - see Table 1; DM - dry matter, FW - fresh weight, CP - crude protein, WSC - water-soluble carbohydrates, NDF - neutral detergent fibre, ADF - acid detergent fibre, $\mathrm{ML}$ - moisture level, $\mathrm{ML} \times \mathrm{CCA}$ - interaction between moisture level and calcium carbonate, SEM - standard error of the mean; ${ }^{A-D}-$ means in the same row with different superscripts are significantly different at $P<0.05$ 

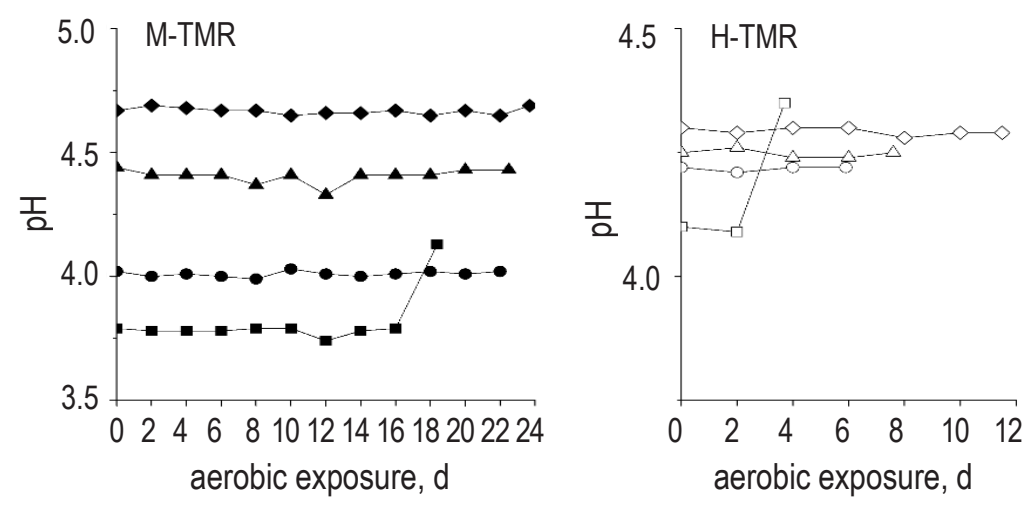

Figure 2. Changes in pH during aerobic deterioration of M-TMR and H-TMR silages ensiled with calcium carbonate $(0,5,15$ and $25 \mathrm{~g} / \mathrm{kg} F W)$;

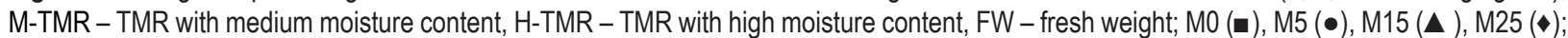
$\mathrm{H} 0$ ( $\square), \mathrm{H} 5(\circ), \mathrm{H} 15(\Delta), \mathrm{H} 25(\diamond)$
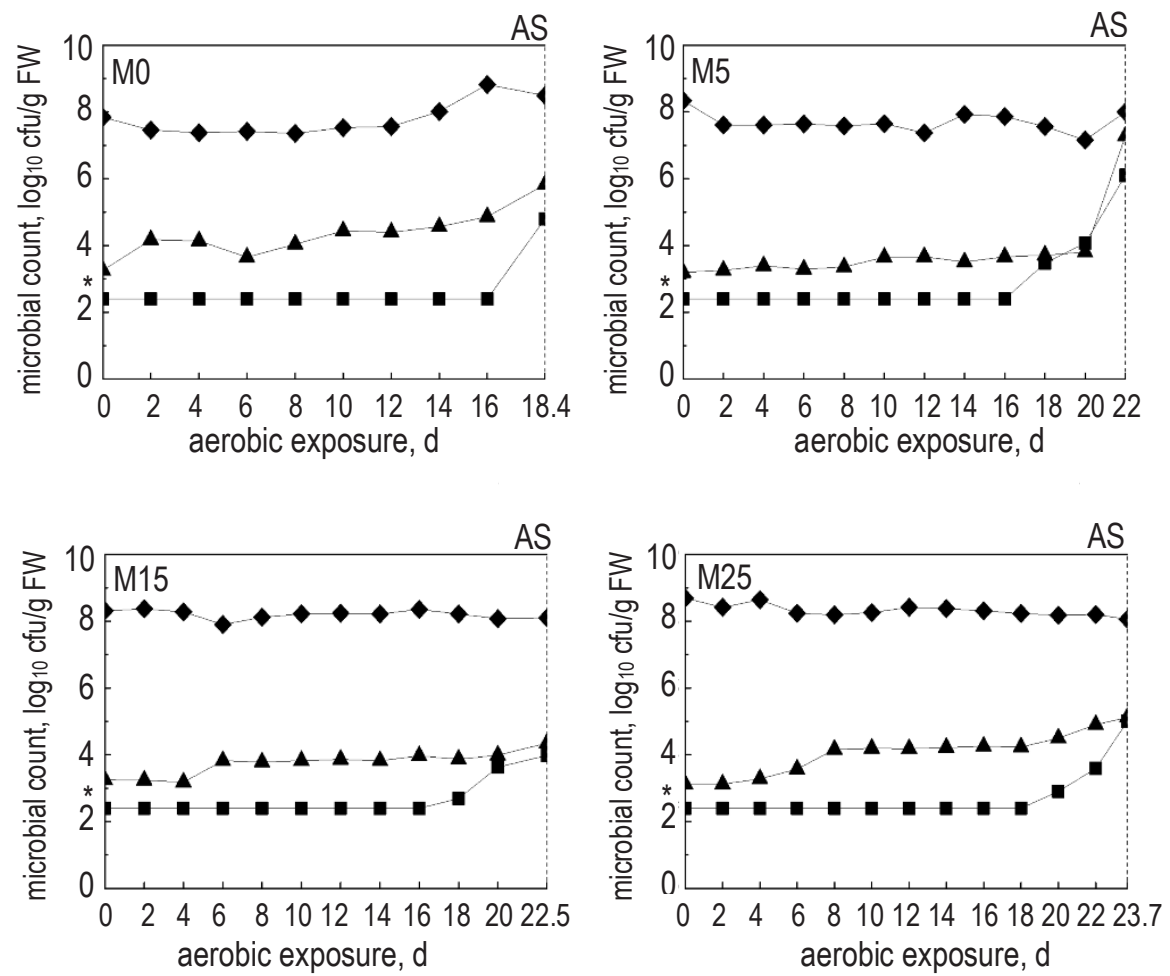

Figure 3. Changes in lactic acid bacteria $(\bullet)$, yeast $(\mathbf{\bullet})$ and aerobic bacteria $(\boldsymbol{\Lambda})$ counts during aerobic deterioration of M-TMR silages ensiled with calcium carbonate of 0 (M0), 5 (M5), 15 (M15) and $25 \mathrm{~g} / \mathrm{kg}$ (M25); M-TMR - TMR with medium moisture content, AS - aerobic stability, $\mathrm{cfu}$ - colony forming units, $\mathrm{FW}$ - fresh weight; ${ }^{*}-2.40$, i.e., $\log _{10} 250 \mathrm{cfu} / \mathrm{g}$, a microbial count below the detection limit was assigned a value corresponding to half of the detection level; the reported values represent the averages from triplicate analyses

No trend of change was observed for the count of LAB in both M-TMR and H-TMR during air exposure and their count remained at approximately $10^{8} \mathrm{cfu} / \mathrm{g} \mathrm{FW}$. However, the count of aerobic bacteria and yeasts both showed obvious growth trends before aerobic deterioration. The count of aerobic bacteria increased from $10^{3}$ to $10^{5} \mathrm{cfu} / \mathrm{g} \mathrm{FW}$ in both M15 and M25, but aerobic bacteria in M0 and M5 increased to $10^{6}$ and $10^{7} \mathrm{cfu} / \mathrm{g} \mathrm{FW}$, respectively. Yeasts counts in M-TMR silages began to grow at day 16 (except M25 where it begun at day 18) and reached about $10^{5} \mathrm{cfu} / \mathrm{g} \mathrm{FW}$ when aerobic deterioration occurred. Likewise, the counts of both aerobic bacteria and yeasts increased before the aerobic deterioration in $\mathrm{H} 5, \mathrm{H} 15$ and $\mathrm{H} 25$, whereas only aerobic bacteria count increased in H0. Furthermore, it was observed that after yeast counts reached about $10^{5} \mathrm{cfu} / \mathrm{g} \mathrm{FW}$, aerobic deterioration occurred in each treatment except H0. 

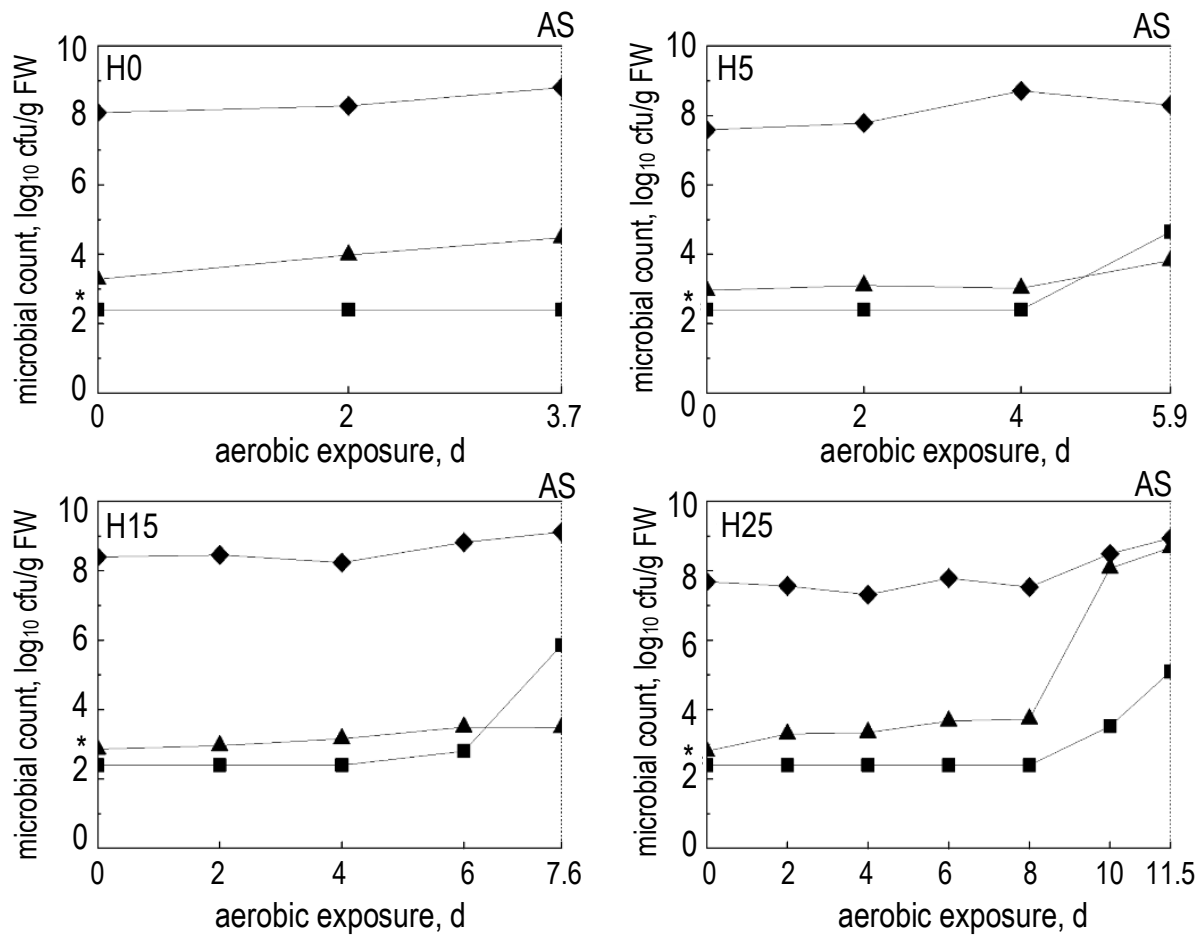

Figure 4. Changes in lactic acid bacteria ( $\downarrow)$, yeast $(\mathbf{\square})$ and aerobic bacteria $(\boldsymbol{\Delta})$ counts during aerobic deterioration of $\mathrm{H}$-TMR silages ensiled with calcium carbonate of $0(\mathrm{H} 0), 5(\mathrm{H} 5), 15(\mathrm{H} 15)$ and $25 \mathrm{~g} / \mathrm{kg}(\mathrm{H} 25) ; \mathrm{H}-\mathrm{TMR}$ - TMR with high moisture content, AS - aerobic stability, cfu - colony forming units, FW - fresh weight; ${ }^{*}-2.40$, i.e., $\log _{10} 250 \mathrm{cfu} / \mathrm{g}$, a microbial count below the detection limit was assigned a value corresponding to half of the detection level; the reported values represent the averages from triplicate analyses

\section{Discussion}

Fermentation quality and chemical composition. TMR usually have sufficient WSC for LAB to ferment it into organic acids under anaerobic condition. The production of large amounts of organic acids leads to an excessive reduction in $\mathrm{pH}$ especially under high moisture and prolonged ensiling conditions, and a resulting decrease in animal feed intake. To assess the effects of CCA on high moisture and prolonged ensiling TMR silage, the pre-ensiling moisture level of TMR was adjusted to 600 and $750 \mathrm{~g} / \mathrm{kg}$ for M-TMR and H-TMR, respectively in the present study. However, the actual values of TMR mixtures before ensiling were 625 and $766 \mathrm{~g} / \mathrm{kg}$, close to the set value but higher than the optimum value $(500 \mathrm{~g} / \mathrm{kg} \mathrm{DM})$ for making TMR silage. The fermentation quality of M-TMR silages was better than H-TMR silages and the results are in agreement with Hao et al. (2015) observing lower fermentation quality and aerobic stability with high moisture levels of TMR silage. The effects of CCA addition on increasing silage $\mathrm{pH}$ and organic acids concentration regardless of the preensiling moisture levels of TMR is likely attributed to the high buffering capacity of CCA. The findings of the present study are in agreement with Wilkin- son and Davies (2013), Haag et al. (2015) and Niu et al. (2018) reports in which improvements in organic acids concentration and buffering capacity of silages were observed. The content of ammonia nitrogen was increased with greater levels of CCA addition. Niu et al. (2018) reported inhibition of proteolysis by rapid decline in $\mathrm{pH}$ during the early days of ensiling in smooth bromegrass silage treated with a mixture of $9 \%$ maize meal and $1.5 \%$ limestone. However, the deamination of peptides and amino acids to ammonia by acid-tolerant microbial activity was kept at a high level. Therefore, the higher contents of ammonia nitrogen in CCA-treated TMR silages may be attributed to higher proteolytic activity primarily of acid-tolerant microorganisms (such as LAB) during ensiling (Saarisalo et al., 2010). Moreover, CCA increased the growth of LAB and inhibited the yeast's growth in this study. This is similar to the findings of Cavali et al. (2010) who reported that the addition of alkaline agents (e.g., lime) could reduce the fungal population and increase the growth of the LAB population. Furthermore, alkaline additives have been used to reduce the fibre fraction and increase the fibre digestibility, or both because of their effects on fibre expansion (hydrolysis), breaking the ester linkages between lignin and hemicellulose, and the hydrogen linkages between cellulose and hemicel- 
lulose (Klopfenstein, 1980; Santos et al., 2009). This may explain the reduction in the NDF and ADF concentrations by the addition of CCA in this study.

Aerobic stability. Exposure of silage to air lead to growth of aerobic bacteria, yeasts and moulds, resulting in temperature rise and decline in nutrient content of silage, and even produce some toxic metabolites harmful to animal health (Schmidt and Kung, 2010; Nkosi et al., 2016). Therefore, improving the aerobic stability is as important as fermentation quality for high moisture TMR silages, since the high moisture content of TMR silage may result in lower aerobic stability, and microbiological dynamics are essential to evaluate TMR silage aerobic stability. Based on our results, the aerobic stability of both M-TMR and H-TMR silages were increased by the application of CCA. This may be attributed to the increasing buffering capacity caused by CCA, since Wilkinson and Davies (2013) reported that a relatively high buffering capacity was contributed to the greater aerobic stability of the ensiled crop. It is known that acetic acid is one of the most effective substances for the inhibition of undesirable microorganisms under aerobic exposure (Danner et al., 2003). The increased acetic acid content lead by the CCA application might be one of the reasons for improving the aerobic stability of TMR silage in the present study. Besides, it is reported that better aerobic stability of TMR silage is also attributed to inhibition of yeast by the rapidly reduced $\mathrm{pH}$ and increased concentrations of organic acids. The higher buffering capacity with CCA made silage $\mathrm{pH}$ more stable, delaying the growth of both aerobic bacteria and yeasts. Therefore, the addition of CCA promoted the conversion of WSC to organic acids and made the acidic environment more stable and unfavourable for aerobic microorganisms. Yeasts brought about the spoilage of TMR silage when their counts are more than $10^{5} \mathrm{cfu} / \mathrm{g} \mathrm{FW}$ (Wang et al., 2016). Likewise, in this study, yeasts count of most TMR silages reached to $10^{5} \mathrm{cfu} / \mathrm{g} \mathrm{FW}$ when aerobic deterioration occurred, indicating that yeasts may be one of the main microorganisms of aerobic deterioration. However, yeasts count of M0 and M15 treatments were under $10^{5} \mathrm{cfu} / \mathrm{g} \mathrm{FW}$ when aerobic deterioration occurred. This is consistent with the findings of Henderson et al. (1979) who reported silages with smaller yeast counts could also be deteriorated when exposed to air. This shows that the count of yeast is not the decisive factor of aerobic deterioration. The hysteresis of aerobic deterioration further indicated that the addition of CCA slowed the growth of yeasts by producing organic acids salt through the reaction between CCA and organic acids. Compared with yeasts and moulds, aerobic bacteria are more sensitive to $\mathrm{pH}$ and undissociated organic acids (Beales, 2010). Moreover, lower $\mathrm{pH}$ is the main factor inhibiting the growth of aerobic bacteria in silages. Similarly, the aerobic bacteria counts were more stable in a higher $\mathrm{pH}$ environment than in lower $\mathrm{pH}$ with the increasing application of CCA in this study. This may be attributed to the high content of organic salts such as lactate having a specific inhibitory effect on bacteria (Houtsma et al., 1993).

\section{Conclusions}

In the current study the influence of calcium carbonate (CCA) on the fermentation quality and aerobic stability of high moisture total mixed rations (TMR) silages was investigated. The application of CCA improved the fermentation quality by the increased $\mathrm{pH}$ and organic acids. Furthermore, it was observed that CCA application inhibits the reproduction of aerobic bacteria and yeasts thereby improving the aerobic stability of the TMR silage. Therefore, ensiling with CCA may be an appropriate strategy to improve the fermentation quality and aerobic stability of relatively high moisture TMR silages.

\section{Acknowledgments}

This work was supported by National Key R\&D Program of China (2017YFD0502100).

\section{References}

AOAC International, 2000. Official Methods of Analysis of AOAC. $17^{\text {th }}$ Edition. Gaithersburg, MD (USA)

Beales N., 2010. Adaptation of microorganisms to cold temperatures, weak acid preservatives, low pH, and osmotic stress: A Review. Compr. Rev. Food Sci. Food Saf. 3, 1-20, https:// https://doi.org/10.1111/j.1541-4337.2004.tb00057.x

Broderick G., Kang J., 1980. Automated simultaneous determination of ammonia and total amino acids in ruminal fluid and in vitro media. J. Dairy Sci. 63, 64-75, https://www.journalofdairyscience. org/article/S0022-0302(80)82888-8/pdf

Cao Y., Takahashi T., Horiguchi K., Yoshida N., Cai Y., 2010. Methane emissions from sheep fed fermented or non-fermented total mixed ration containing whole-crop rice and rice bran. Anim. Feed Sci. Technol. 157, 72-78, https://doi.org/10.1016/j.anifeedsci.2010.02.004

Cavali J., Pereira O.G., Valadares Filho S.d.C., Santos E. M., Carvalho G.G.P. d., Santos M. V., Porto M.O., Rodrigues J.F.H., 2010. Bromatological and microbiological characteristics of sugarcane silages treated with calcium oxide. Rev. Bras. Zootec. 39, 13981408, https://doi.org/10.1590/s1516-35982010000700002

Danner H., Holzer M., Mayrhuber E., Braun R., 2003. Acetic acid increases stability of silage under aerobic conditions. Appl. Environ. Microbiol. 69, 562-567, https://doi.org/10.1128/ AEM.69.1.562-567.2003 
Gao X., Oba M., 2014. Relationship of severity of subacute ruminal acidosis to rumen fermentation, chewing activities, sorting behavior, and milk production in lactating dairy cows fed a high-grain diet. J. Dairy Sci. 97, 3006-3016, https://doi. org/10.3168/jds.2013-7472

Haag N.L., Steinbrenner J.R., Demmig C., Nägele H.J., Oechsner $H ., 2015$. Influence on lactic acid content in maize silage variations by manganese supplementation. Ind. Crops Prod. 79, 146-151, https://doi.org/10.1016/j.indcrop.2015.11.030

Hao W., Wang H.L., Ning T.T., Yang F.Y., Xu C.C., 2015. Aerobic stability and effects of yeasts during deterioration of non-fermented and fermented total mixed ration with different moisture levels. Asian-Australas. J. Anim Sci. 28, 816-826, https://doi. org/10.5713/ajas.14.0837

Henderson A.R., Ewarta J.M., Robertson G.M., 1979. Studies on the aerobic stability of commercial silages. J. Sci. Food Agric. 30 223-228, https://doi.org/ 10.1002/jsfa.2740300302

Houtsma P.C., Wit J.C.D., Rombouts F.M., 1993. Minimum inhibitory concentration (MIC) of sodium lactate for pathogens and spoilage organisms occurring in meat products. Int. J. Food Microbiol. 20, 247-257, https://doi.org/10.1016/01681605(93)90169-H

Klopfenstein T., 1980. Increasing the nutritive value of crop residues by chemical treatment. In: J. Tal Huber (Editor). Upgrading Residues and By-Products for Animals. CRC Press, Boca Raton, FL (USA), pp. 39-60

Klosterman E.W., Johnson R.R., Scott H.W., Moxon A., Van Stavern J., 1960. Whole plant and ground ear corn silages, their acid content, feeding value and digestibility. J. Anim. Sci. 19, 522-532, https://doi.org/10.2527/jas1960.192522x

Li X., Hansen W., Otterby D., Linn J., Kuehn C., 1992. Effect of additives on fermentation of corn silage containing different amounts of added nitrate nitrogen. J. Dairy Sci. 75, 15551561, https://doi.org/10.3168/jds.S0022-0302(92)77912-0

Miyaji M., Matsuyama H., Hosoda K., Nonaka K., 2013. Milk production, nutrient digestibility and nitrogen balance in lactating cows fed total mixed ration silages containing steam-flaked brown rice as substitute for steam-flaked corn, and wet food by-products. Anim. Sci. J. 84, 483-488, https://doi.org/10.1111/asj.12026

Miyaji M., Matsuyama H., Nonaka K., 2017. Effect of ensiling process of total mixed ration on fermentation profile, nutrient loss and in situ ruminal degradation characteristics of diet. Anim. Sci. J. 88, 134-139, https://doi.org/10.1111/asj.12610

Niu D.Z., Zheng M.L., Zuo S.S., Jiang D., Xu C.C., 2018. Effects of maize meal and limestone on the fermentation profile and aerobic stability of smooth bromegrass (Bromus inermis Leyss) silage. Grass Forage Sci. 73, 622-629, https://doi. org/10.1111/gfs.12355

Nkosi B.D., Meeske R., Langa T., Motiang M.D., Modiba S., Mkhize N.R., Groenewald I.B., 2016. Effects of ensiling forage soybean (Glycine max (L.) Merr.) with or without bacterial inoculants on the fermentation characteristics, aerobic stability and nutrient digestion of the silage by Damara rams. Small Rumin. Res. 134, 90-96, https://doi.org/10.1016/j.smallrumres.2015.12.001
Oladosu Y., Rafii M.Y., Abdullah N., Magaji U., Hussin G., Ramli A., Miah G., 2016. Fermentation quality and additives: A case of rice straw silage. BioMed Res. Int. 2016, 1-14, https://doi. org/10.1155/2016/7985167

Saarisalo E., Skytta E., Haikara, A.T., Jaakkola S., 2010. Screening and selection of lactic acid bacteria strains suitable for ensiling grass. J. Appl. Microbiol. 102, 327-336, https://doi. org/10.1111/j.1365-2672.2006.03103.x

Santos M.C., Nussio L.G., Mourão G.B., Schmidt P., Mari L.J., Ribeiro J.L., Queiroz O.C.M., Zopollatto M., Sousa D.dP., Sarturi J.O., 2009. Nutritive value of sugarcane silage treated with chemical additives. Sci Agric. 66, 159-163, https://doi.org/10.1590/ s0103-90162009000200003

Schmidt R.J., Kung Jr. L., 2010. The effects of Lactobacillus buchneri with or without a homolactic bacterium on the fermentation and aerobic stability of corn silages made at different locations. J. Dairy Sci. 93, 1616-1624, https://doi.org/10.3168/ jds.2009-2555

Thomas T.A., 1977. An automated procedure for the determination of soluble carbohydrates in herbage. J. Sci. Food Agric. 28, 639-642, https://doi.org/10.1002/jsfa.2740280711

Van Soest P.J., Robertson J., Lewis B., 1991. Methods for dietary fiber, neutral detergent fiber, and nonstarch polysaccharides in relation to animal nutrition. J. Dairy Sci. 74, 3583-3597, https:// doi.org/10.3168/jds.S0022-0302(91)78551-2

Wang H.L., Ning T.T., Hao W., Zheng M.L., Xu C.C., 2016. Dynamics associated with prolonged ensiling and aerobic deterioration of total mixed ration silage containing whole crop corn. AsianAustralas J. Anim. Sci. 29, 62-72, https://doi.org/10.5713/ ajas. 15.0319

Weinberg Z.G., Chen Y., Miron D., Raviv Y., Nahim E., Bloch A., Yosef E., Nikbahat M., Miron J., 2011. Preservation of total mixed rations for dairy cows in bales wrapped with polyethylene stretch film - A commercial scale experiment. Anim. Feed Sci. Technol. 164, 125-129, https://doi.org/10.1016/j.anifeedsci.2010.11.016

Wilkinson J., Davies D., 2013. The aerobic stability of silage: key findings and recent developments. Grass Forage Sci. 68, 1-19, https://doi.org/10.1111/j.1365-2494.2012.00891.x

Xu C.C., Cai Y.M., Moriya N., Ogawa M., 2007. Nutritive value for ruminants of green tea grounds as a replacement of brewers' grains in totally mixed ration silage. Anim Feed Sci Technol. 138, 228-238, https://doi.org/10.1016/j.anifeedsci.2006.11.014 